\title{
Strongyloidiasis in northern Vietnam: epidemiology, clinical characteristics and molecular diagnosis of the causal agent
}

\author{
Nguyen Van De ${ }^{1 *}$, Pham Ngoc Minh ${ }^{1}$, Le Van Duyet ${ }^{2}$ and Santiago Mas-Coma ${ }^{3}$
}

\begin{abstract}
Background: Strongyloidiasis is a health problem in Vietnam, but appropriate information is still limited. The aim of this study was to determine the prevalence, geographical distribution, epidemiological aspects, symptoms and other health indicators of Strongyloides stercoralis infections in patients from 27 provinces of northern Vietnam attending the Hanoi Medical University Hospital during 2016 and 2017.

Methods: Blood samples of 2000 patients were analyzed for S. stercoralis infection with an IgG ELISA test. Seroprevalence was analyzed by gender, age group, locality of origin (rural or urban areas) and symptoms. Stools from the seropositive patients were examined for the detection of worms which were subsequently used for species identification by morphology and rDNA ITS1 sequencing.

Results: A seroprevalence of $20 \%$ was detected, showing an increasing prevalence from young to older age groups but without significant gender difference. Seroprevalence was higher in rural areas than in urban areas, both in general and individually in all provinces without exception, and lower in the mountainous areas than in the large valley lowlands. The follow-up of the 400 patients showed eosinophilia in 100\% of cases, diarrhoea in $64.5 \%$, digestion difficulties in 58.0\%, stomachache in 45.5\%, stomach and duodenal ulcers in $44.5 \%$, itching in $28.0 \%$ and fever in $9.5 \%$. The prevalence of symptoms and signs were also higher in older age groups than in younger age groups. Worms were detected in stools of 10.5\% of the patients. Sequencing of a 501-bp nuclear ribosomal DNA ITS1 fragment allowed for the verification of infection by Strongyloides stercoralis.
\end{abstract}

Conclusions: To our knowledge, this study is the largest survey of human strongyloidiasis in Vietnam so far and the first molecular identification of this nematode species in this country. Long-term chronicity may probably be usual in infected subjects, mainly in the older age groups.

Keywords: Strongyloides stercoralis, Epidemiology, Geographical distribution, Symptomatology, Diagnosis, ITS1 sequence, Vietnam

\section{Background}

Strongyloidiasis is a helminthic disease included among the group of soil-transmitted diseases (STDs), although still not included within the neglected tropical diseases list (NTDs) [1]. It is caused by small-sized, soil-transmitted nematodes whose females and larval stages infect humans, dogs and cats [2-4]. Their life-cycle includes

\footnotetext{
*Correspondence: ngvdeyhn@gmail.com

${ }^{1}$ Hanoi Medical University, 01 Ton That Tung, Hanoi, Vietnam

Full list of author information is available at the end of the article
}

a generation of adult males and females free-living in humid soil and a parasitic parthenogenetic female generation infecting the host's intestine. Human infection takes place by transcutaneous or transmucosal penetration of strongyloid filariform larvae issued from rhabditiform larvae in the soil under appropriate conditions. After penetration, infective larvae migrate through the blood system, proceeding to the lungs via the heart and from the alveoli to the trachea and subsequent swallowing into the oesophagus, stomach and small intestine, mainly the duodenum, where adult females develop and 
produce eggs by parthenogenesis. Rhabditiform larvae hatch from these eggs in the intestine and are expelled with the faeces [5].

Strongyloides stercoralis may cause dermatitis at the site of invasion, lesions in the lungs and bronchitis due to the migrating larval stage [6]. The main lesions in strongyloidiasis are seen in the digestive tract, especially the duodenum and the upper part of the jejunum, but may occur also in the bile and pancreatic ducts. Strongyloidiasis may cause intermittent symptoms that mostly affect the intestine (abdominal pain and intermittent or persistent diarrhoea), the lungs (cough, wheezing, chronic bronchitis) or skin (pruritus, urticaria) [1]. Once autoinfection starts, additional lesions caused by the larvae aggravate the mucosal damage such as erosions and ulcers, with the possible destruction of the muscular layer which may lead to perforation. Symptoms include abdominal discomfort, right upper abdominal pain, diarrhoea, irregular fever and cough. These symptoms become aggravated in autoinfection including mucous, bloody diarrhoea, anaemia, edema and ascites [7].

Clinical complications in organs other than the duodenum have also been described [8-10]. The health effects of strongyloidiasis on pregnant women should also be considered [11]. Autoinfection of the patients may lead to highly problematic, severe hyperinfections which are almost invariably fatal [12-18].

Strongyloidiasis is also known as one of the few helminthiases linked to immunosuppression situations, such as in AIDS $[19,20]$, organ transplantation post-surgery [21] or other processes [22, 23]. This intestinal disease may secondarily give rise to the so-called larva currens, dermic lesions remembering cutaneous larva migrans by hookworms but differentiated from the latter by the linear courses of the skin lesions, their higher movement speed, their appearance mostly at the level of the back or abdomen, lower eritema and the absence of secondary bacterial infection after scratching [24].

For diagnosis of patients, coprology for rhabditiform larvae detection in the patient's stools has been noted to be of low sensitivity, and serology has been therefore recommended as diagnostic method [25-27].

Strongyloidiasis is widely distributed, with an estimated 30 to 100 million infected individuals throughout the world [27], especially in the tropical regions characterized by high temperatures and humidity and poor hygienic conditions. In Africa, the range of infection prevalences in the communities varies from $0.1 \%$ in the Central African Republic up to $91.8 \%$ in Gabon. In the Gisagara District, Southern Province, Rwanda, S. stercoralis infection was found to be $17.4 \%$ [28]. In South and Central America, Haiti reports a prevalence of 1.0\%, while in Peru the infection prevalence is as high as $75.3 \%$ [3].

In Southeast Asia, another highly endemic part of the world, several countries reported infection prevalences within a comparably small range [29-31]. In Cambodia the infection prevalence was $17.5 \%$, in Thailand $23.7 \%$ and in Lao PDR 26.2\% [3].

In Vietnam, there are already reports of human infection [32-36]. However, studies on strongyloidiasis are limited. Using stool examinations, the results in communities showed a prevalence of $0.2-2.5 \%$ [6]. When seroimmunological tests were used, the prevalence detected was higher, such as strongyloidiasis infection prevalences of $29 \%$ in the stomachache patient group and $7.6 \%$ at the community level [37], and $7.6 \%$ in other communities [33]. In recent years, many thousands of strongyloidiasis infections have been detected in hospitals. However, an overview about the strongyloidiasis situation in Vietnam, particularly with a wider evaluation by analyzing a larger number of subjects, a study to assess Strongyloides stercoralis infection in the northern part of the country, including the capital Hanoi and surroundings, and a characterization of the causal agent species by a molecular method, is still needed.

\section{Methods}

\section{Sample collection}

A total of 2000 adult patients ( $>15$ years-old) visited the Hanoi Medical University Hospital from 2016 to 2017 for examination. The Hanoi Medical University Hospital receives patients from throughout the whole country, although only patients from northern Vietnam were considered for this survey. The present study only included patients presenting with clear symptoms sent by polyclinical doctors. The Strongyloides stercoralis test was applied as a routine diagnosis by the Parasitology Department of the hospital.

Information collected consisted of gender (male/ female), locality of origin (from rural or urban areas in each province) (Fig. 1), age group (16-25; 26-35; 36-45; $46-55$; 56-65; and $>65$ years-old), data of serum collection (S. stercoralis IgG ELISA tests), blood characteristics and clinical symptoms. The following patients were chosen: those who presented with eosinophilia ( $>8 \%$, according to the normal physiology of Vietnamese inhabitants) and positive ELISA test using S. stercoralis antigen (IgG ELISA kit of a DRG Instruments $\mathrm{GmbH}$, Springfield, USA) with a sensitivity of $100 \%$ and a specificity of $98 \%$. Parasitic samples included 85 worms in total collected from patients and kept in $70 \%$ ethanol at $-20{ }^{\circ} \mathrm{C}$ for the molecular identification of the causal agent species. The present study did only focus on strongyloidiasis, stool 


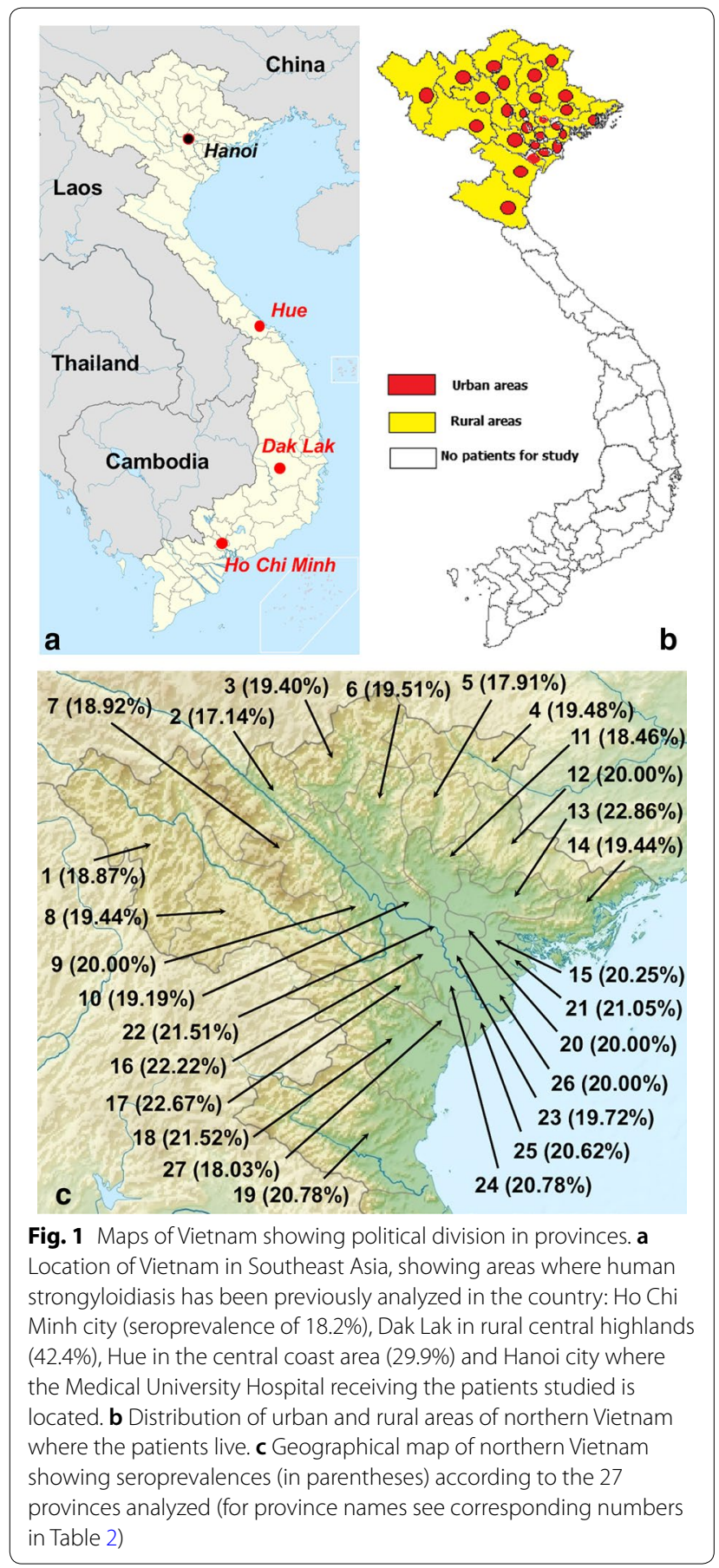

samples from the patients being examined the day of collection with microscopic preparations of stool smears.

\section{Clinical analyses}

Main symptoms considered included diarrhoea, digestive disorders, stomachache, itching, fever and bloody stool. Additionally, the signs of eosinophilia, and stomach and duodenal ulcers (using gastroscopic endoscope) were considered, as well as the collection of larvae in the stool and lesions of worms under the skin.

\section{Specific identification of the causal agent}

Morphological identification of the nematode worms obtained from the patients was made using the reference guide of Miyazaki [7].

\section{Molecular characterization of the parasite}

For this purpose, a 501-bp sequence of the first internal transcribed spacer ITS1 of the nuclear ribosomal DNA from the collected worms was obtained and analyzed. Indeed, the two spacers ITS1 and ITS2 are known as the best markers for the identification of species in invertebrates in general [38]. Larvae sequenced were from 42 patients from different geographical origins in the zone studied.

For DNA isolation performance, Qiagen kits (DNeasy Blood \& Tissue Kit; Qiagen, Gremantown, MD, USA) were used for the extraction of total DNA from Strongyloides stercoralis in accordance with the manufacturer's protocol. In brief, worms were resuspended in the 100 $\mu \mathrm{l}$ of the manufacturer's lysis buffer ATL ( $>8 \mathrm{mM}$ EDTA, $>0.5 \%$ SDS) containing $20 \mu \mathrm{l}$ of proteinase $\mathrm{K}$ and incubated at $56{ }^{\circ} \mathrm{C}$ for $30 \mathrm{~min}$. Thereafter, $4 \mu \mathrm{l}$ of RNase and $200 \mu \mathrm{l}$ of ATL buffer were added and treated in accordance with the manufacturer's protocol (for a microfuge scale preparation).

PCR for amplification of the 501-bp fragment of the ITS- 1 was performed in a $50 \mu \mathrm{l}$ volume. PCR reactions were performed in $10 \mathrm{mM}$ Tris- $\mathrm{HCl}, \mathrm{pH} 8.4,50 \mathrm{mM}$ $\mathrm{KCl} ; 3.0 \mathrm{mM} \mathrm{MgCl} 2250 \mu \mathrm{M}$ each of dATP, dCTP, dGTP and dTTP; 50 pmol of each primer with $1 \mathrm{U}$ Taq polymerase (Promega, Madison, USA). The following primers were used in separate reaction mixes: S-F $\left(5^{\prime}\right.$-ATC CTT CCA ATC GCT GTT GT-3') and S-R (5'-TTT CGT GAT GGG CTA ATT CC-3'); Nested-F (5'-GTA ACA AGG TTT TCG TAG GTG AA- $3^{\prime}$ ) and Nested-R (5'-ATT TAG TTT CTT TTC CTC CGC TT-3') [39]. Amplification was first conducted for 25 cycles using the primer set S-F and F-R. Then, $2 \mu \mathrm{l}$ of each F-S and F-R amplicon was transferred to a fresh tube containing the same PCR reaction buffer with the primer set Nested-F and F-S and another with the primer set Nested-R and F-R, and amplified for another 35 cycles. Cycling was performed in a Genius Thermal Cycler (Techne, Essex, UK) using the following parameters: initial denaturation at $94{ }^{\circ} \mathrm{C}$ for $5 \mathrm{~min}$, followed by 25 cycles ( 35 cycles in the second PCR) of $94{ }^{\circ} \mathrm{C}$ for $30 \mathrm{~s}$ (denaturation), $55^{\circ} \mathrm{C}$ for 30 $\mathrm{s}$ (annealing) and $72{ }^{\circ} \mathrm{C}$ for $30 \mathrm{~s}$ (extension), followed by a final extension step at $72{ }^{\circ} \mathrm{C}$ for $5 \mathrm{~min}$.

Dideoxy sequencing was performed using BigDye ${ }^{\mathrm{TM}}$ Terminator Chemistry v.3.1 (Applied Biosystems, Foster 
City, CA, USA) according to the manufacturer's instructions. Forward and reverse primers for Strongyloides stercoralis were used as sequencing primers using the $\mathrm{ABI}$ 3130 Bioanalyzer (Applied Biosystems).

Multiple sequence alignments were performed by using the ATGC software v.7.0.2 and the Clustal W program to determine nucleotide sequence similarities. Phylogenetic trees were constructed in MEGA using the neighbourjoining (NJ) cluster algorithm with evolutionary distances estimated using the Kimura 2-parameter model; bootstrapping was performed using 1000 pseudoreplicates.

\section{Results}

\section{Epidemiological aspects}

From 2000 adult patients comprising 1022 females and 978 males who visited Hanoi Medical University Hospital, a total of 400 patients tested positive by the ELISA test of S. stercoralis antigen, furnishing a seroprevalence of S. stercoralis of $20 \%$. All larvae-positive individuals proved to be seropositive. Male patients were more frequently seroreactive than females (214/1022, 20.94\%; and $186 / 978,19.02 \%$, respectively, but the difference was not significant; $P>0.05$ ). The prevalence of strongyloidiasis was higher in the older age groups than in the younger age groups (Table 1).

Strongyloides stercoralis infection also showed to be higher in rural areas than in urban areas $(311 / 1390=22.37 \%$ and $89 / 610=14.59 \% ; \quad P<0.05)$, both in general and individually in all provinces without exception (Table 2). Interestingly, however, seroprevalences proved to be lower in the mountainous areas than in the large valley lowlands (Fig. 1c).

\section{Analysis of symptoms and signs}

Of the 400 strongyloidiasis-seropositive patients, results showed that the main symptoms included diarrhoea $64.5 \%$ (258/400), digestive disorder 58.0\% (232/400), stomachache $45.5 \%(182 / 400)$, itching $28.0 \%(112 / 400)$, fever 9.5\% (38/400) and bloody stool 8.0\% (32/400). Signs included eosinophilia 100\% (400/400) and stomach and duodenal ulcers $44.5 \%$ (178/400). The symptoms and signs described were not seen in seronegative and larvaenegative patients. There was no difference in symptoms and signs between larvae-positive and larvae-negative individuals.

Nematode rhabditiform larvae of S. stercoralis (Fig. 2) were collected from stools in $10.5 \%$ of the patients (42/400), namely in 33 among $328(10.06 \%)$ in the $16-60$ years-old group and 9 out of $72(12.50 \%)$ in the $>60$ years-old group. Skin lesions showing a creeping eruption of the type of cutaneous larva migrans (Fig. 3) were detected in $3.5 \%$ of the patients $(14 / 400)$.

When analyzed regarding age, the different groups showed slowly gradually increasing curves from the younger to the older groups (Table 1, Fig. 4). Moreover, these symptoms were more frequently detected in patients from the rural areas than in those from the urban areas.

\section{DNA sequencing}

Nematode larvae obtained from patient's stools were used for the molecular identification and characterization of the causal agent. A 501-nucleotide fragment of the ITS1 of S. stercoralis from Vietnam was sequenced and compared with different S. stercoralis sequences from GenBank, including Iranian and Australian $S$. stercoralis $[40,41]$ (Table 3 ). The results showed a high nucleotide similarity between Vietnamese $S$. stercoralis and other sequences of this species on GenBank at a level of $99 \%$ (Fig. 5). In the alignment, only four positions showing transitions and another four positions showing insertions/deletions (indels) appeared scattered throughout most of the sequence length. The majority of the nucleotide differences appeared

Table 1 Seroprevalence and symptoms of strongyloidiasis according to age groups

\begin{tabular}{|c|c|c|c|c|c|c|}
\hline & \multicolumn{6}{|c|}{ Age groups (years) ${ }^{a}$} \\
\hline & $16-25$ & $26-35$ & $36-45$ & $46-55$ & $56-65$ & $>65$ \\
\hline Seroprevalence & $19.46(58 / 298)$ & $19.02(70 / 268)$ & $19.27(69 / 358)$ & $20.50(68 / 322)$ & $20.45(73 / 357)$ & $21.55(64 / 297)$ \\
\hline Diarrhoea & $53.45(31 / 58)$ & $60.00(42 / 70)$ & $65.22(45 / 69)$ & $65.15(43 / 66)$ & $67.12(49 / 73)$ & $75.00(48 / 64)$ \\
\hline Digestive disorder & $51.72(30 / 58)$ & $52.85(37 / 70)$ & $56.52(39 / 69)$ & $62.12(41 / 66)$ & $58.90(43 / 73)$ & $65.63(42 / 64)$ \\
\hline Stomachache & $43.10(25 / 58)$ & $41.42(29 / 70)$ & $44.93(31 / 69)$ & $45.45(30 / 66)$ & $47.95(35 / 73)$ & $50.00(32 / 64)$ \\
\hline Stomach and duodenal ulcers & $39.66(24 / 58)$ & $42.85(30 / 70)$ & $44.93(30 / 69)$ & $43.94(28 / 66)$ & $45.21(32 / 73)$ & $51.56(33 / 64)$ \\
\hline Itching & $24.14(14 / 58)$ & $24.29(17 / 70)$ & $24.64(17 / 69)$ & $28.79(19 / 66)$ & $31.51(25 / 73)$ & $34.38(22 / 64)$ \\
\hline Fever & $5.17(2 / 58)$ & $7.14(5 / 70)$ & $10.14(7 / 69)$ & $9.10(6 / 66)$ & $10.96(8 / 73)$ & $14.06(9 / 64)$ \\
\hline Bloody stool & $3.45(2 / 58)$ & $5.71(4 / 70)$ & $8.70(6 / 69)$ & $9.10(6 / 66)$ & $9.59(7 / 73)$ & $10.94(7 / 64)$ \\
\hline
\end{tabular}

${ }^{a}$ Data are given as prevalence (in \%) (no. of positive patients/no. of examined patients) 
Table 2 Geographical distribution of strongyloidiasis in the urban areas and the rural areas of northern Vietnam according to province

\begin{tabular}{|c|c|c|c|c|c|c|c|}
\hline \multirow[t]{2}{*}{ Code } & \multirow[t]{2}{*}{ Province } & \multicolumn{2}{|c|}{ Urban areas } & \multicolumn{2}{|l|}{ Rural areas } & \multicolumn{2}{|l|}{ Total } \\
\hline & & $n / N$ & $\%$ & $n / N$ & $\%$ & $n / N$ & $\%$ \\
\hline 1 & Lai Chau & $2 / 16$ & 12.50 & $8 / 37$ & 21.62 & $10 / 53$ & 18.87 \\
\hline 2 & Lao Cai & $2 / 19$ & 10.53 & $10 / 51$ & 19.61 & $12 / 70$ & 17.14 \\
\hline 3 & Ha Giang & $2 / 18$ & 11.11 & $11 / 49$ & 22.45 & $13 / 67$ & 19.40 \\
\hline 4 & Cao Bang & $2 / 15$ & 13.33 & $10 / 48$ & 20.83 & $12 / 63$ & 19.48 \\
\hline 5 & Bac Kan & $2 / 16$ & 12.50 & $10 / 51$ & 19.61 & $12 / 67$ & 17.91 \\
\hline 6 & Tuyen Quang & $4 / 27$ & 14.81 & $12 / 55$ & 21.82 & $16 / 82$ & 19.51 \\
\hline 7 & Yen Bai & $3 / 22$ & 13.64 & $11 / 52$ & 21.15 & $14 / 74$ & 18.92 \\
\hline 8 & Son La & $3 / 21$ & 14.29 & $11 / 51$ & 21.57 & $14 / 72$ & 19.44 \\
\hline 9 & PhuTho & $4 / 28$ & 14.29 & $12 / 52$ & 23.08 & $16 / 80$ & 20.00 \\
\hline 10 & Vinh Phuc & $2 / 19$ & 10.52 & $9 / 45$ & 20.00 & $11 / 64$ & 17.19 \\
\hline 11 & Thai Nguyen & $2 / 18$ & 11.11 & $10 / 47$ & 21.28 & $12 / 65$ & 18.46 \\
\hline 12 & Lang Son & $2 / 17$ & 11.76 & $11 / 48$ & 22.92 & $13 / 65$ & 20.00 \\
\hline 13 & Bac Giang & $4 / 21$ & 19.05 & $12 / 49$ & 24.49 & $16 / 70$ & 22.86 \\
\hline 14 & Quang Ninh & $3 / 19$ & 15.79 & $11 / 53$ & 20.75 & $14 / 72$ & 19.44 \\
\hline 15 & Hai Duong & $4 / 24$ & 16.67 & $13 / 55$ & 23.64 & $16 / 79$ & 20.25 \\
\hline 16 & Ha Tay & $4 / 25$ & 16.00 & $13 / 56$ & 23.21 & $18 / 81$ & 22.22 \\
\hline 17 & Hoa Binh & $4 / 21$ & 19.05 & $13 / 54$ & 24.07 & $17 / 75$ & 22.67 \\
\hline 18 & Thanh Hoa & $4 / 25$ & 16.00 & $13 / 54$ & 24.07 & $17 / 79$ & 21.52 \\
\hline 19 & Nghe An & $4 / 24$ & 16.67 & $12 / 53$ & 22.64 & $16 / 77$ & 20.78 \\
\hline 20 & Bac Ninh & $4 / 23$ & 17.39 & $11 / 52$ & 21.15 & $15 / 75$ & 20.00 \\
\hline 21 & Hai Phong & $4 / 24$ & 16.67 & $12 / 52$ & 23.08 & $16 / 76$ & 21.05 \\
\hline 22 & Ha Noi & $6 / 35$ & 17.14 & $14 / 58$ & 24.14 & 20/93 & 21.51 \\
\hline 23 & Hung Yen & $3 / 22$ & 13.64 & $11 / 49$ & 22.45 & $14 / 71$ & 19.72 \\
\hline 24 & Ha Nam & $3 / 21$ & 14.29 & $13 / 56$ & 23.21 & $16 / 77$ & 20.78 \\
\hline 25 & Nam Dinh & $5 / 36$ & 13.89 & $15 / 61$ & 24.59 & 20/97 & 20.62 \\
\hline 26 & Thai Binh & $5 / 35$ & 14.29 & $14 / 60$ & 23.33 & $19 / 95$ & 20.00 \\
\hline \multirow[t]{2}{*}{27} & Ninh Binh & $2 / 19$ & 10.53 & $9 / 42$ & 21.43 & $11 / 61$ & 18.03 \\
\hline & $\begin{array}{l}\text { Whole northern part of } \\
\text { Vietnam }\end{array}$ & $89 / 610$ & 14.59 & $311 / 1390$ & 22.37 & $400 / 2000$ & 20.00 \\
\hline
\end{tabular}

For the geographical distribution of the provinces see Fig. 1c

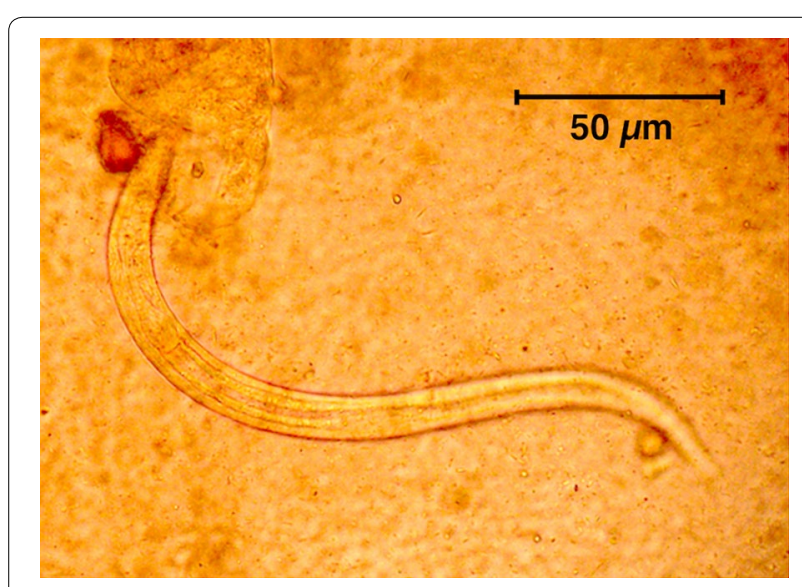

Fig. 2 Rhabditiform larva collected from stools of an infected patient from northern Vietnam. Note the rhabditoid oesophagus on the left concentrated in the final part of the sequence, from position 471 , including mostly transversions and very scarce indels and transitions throughout 13 varying positions. In the phylogenetic tree including other human-infecting nematodes, Vietnamese S. stercoralis clustered in one group together with $S$. stercoralis sequences from GenBank with a $100 \%$ support value (Fig. 6).

\section{Discussion}

The seroprevalence found among a total of 2000 patients from all 27 provinces of northern Vietnam (Fig. 1b, c) who visited Hanoi Medical University Hospital, including an infection prevalence higher in the rural areas than in the urban areas (Table 2), may be considered as relatively high, although it agrees well with seroprevalence data 

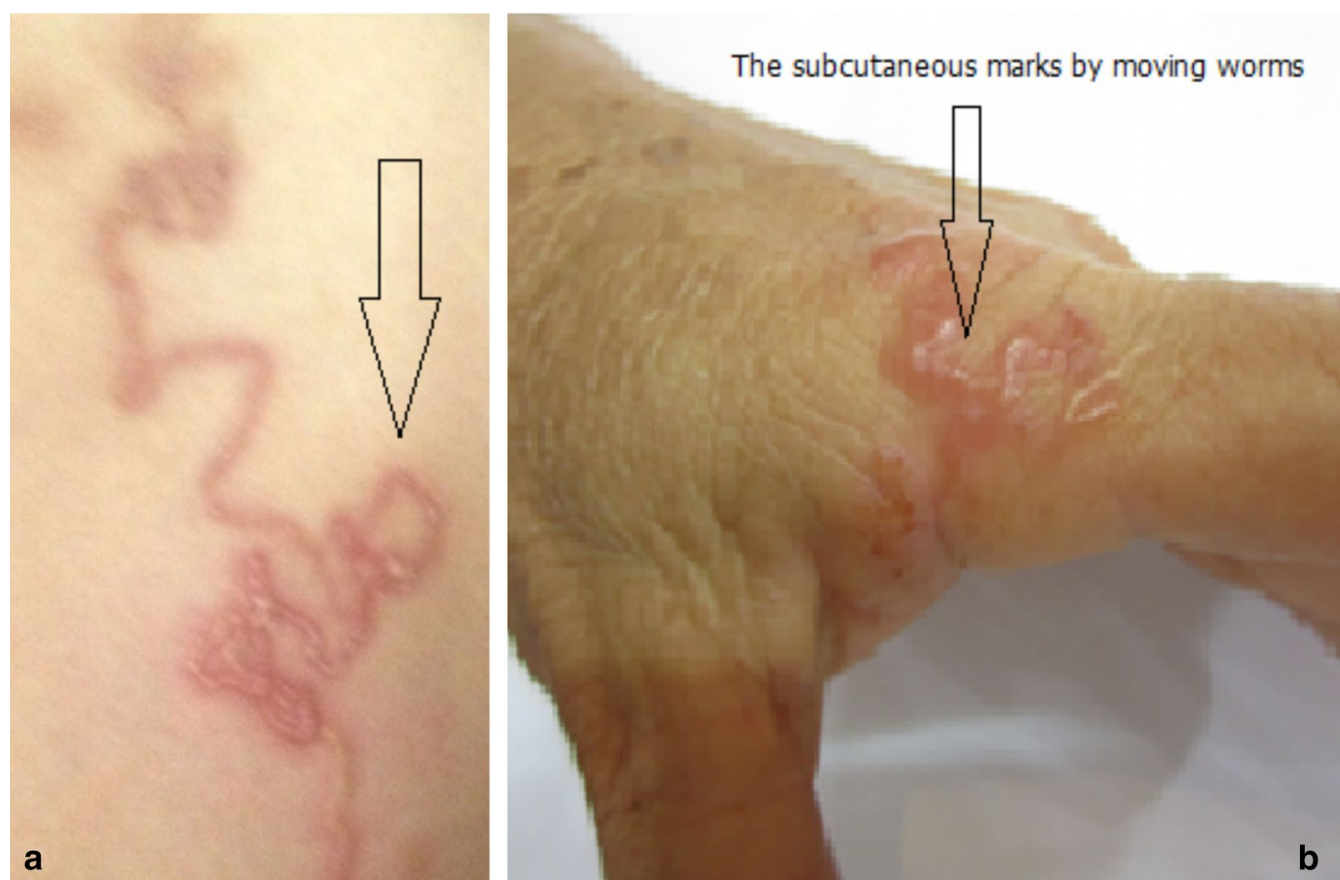

Fig. 3 Skin lesions found in Vietnamese patients showing two creeping eruptions $(\mathbf{a}, \mathbf{b})$ of the type of cutaneous larva migrans

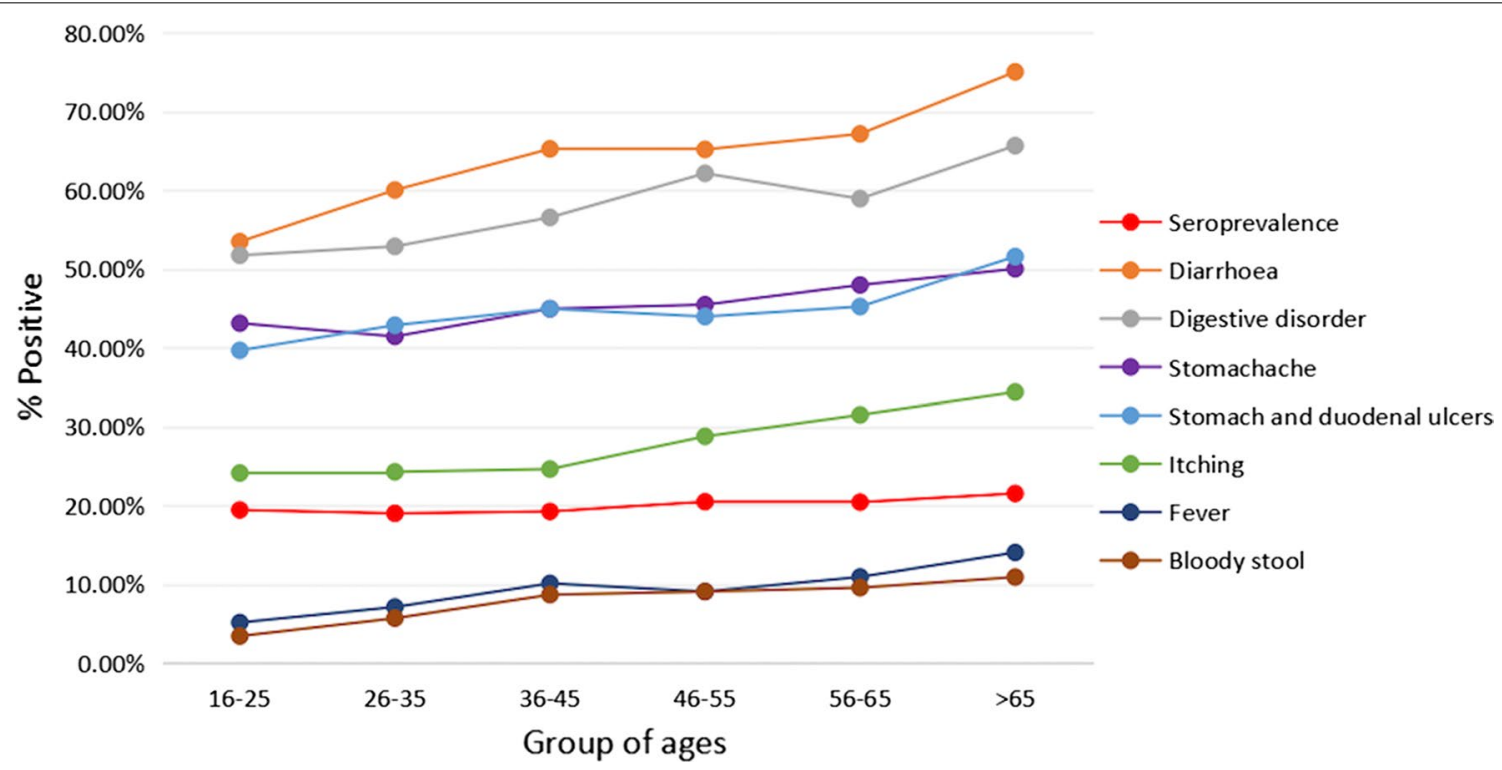

Fig. 4 Seroprevalence and symptoms found in strongyloidiasis patients from northern Vietnam related to the age group

reported previously from this country. In a study of sera selected from a serum bank, the seroprevalence showed to be highest in the rural central highlands $(42.4 \%$ out of 335 adult subjects from Dak Lak), followed by the central coast area (29.9\% of 335 adult subjects from Hue), and with lower prevalences in the big cities such as in Ho Chi
Minh (18.2\% of 335 adult subjects) and Hanoi (26.0\% of 335 adult subjects) [35]. Our study of a larger number of subjects revealed that in the Hanoi capital area strongyloidiasis prevalence is somewhat lower, i.e. $20 \%$, although this is still a worrying public health scenario given the morbidity and potential mortality of this nematode 
Table 3 Sequences of the internal transcribed spacer 1 (ITS1) of Strongyloides stercoralis from Vietnam and other countries

\begin{tabular}{llllll}
\hline Notation & Origin & Host & Length (bp) & GenBank ID & Reference \\
\hline Sster-VN & Vietnam & Human & 501 & MN607960 & This study \\
Sster1 & Iran & - & 501 & EF545004.1 & Moghaddassani et al. [40] \\
Sster2 & Iran & - & 501 & EF653265.1 & Moghaddassan et al. [40] \\
Sster3 & Australia & - & JX489140.1 & Sultana et al. [41] \\
Sster4 & Australia & - & 501 & JX489145.1 & Sultana et al. [41] \\
Sster5 & Iran & - & 501 & EF653266.1 & Moghaddassan et al. [40] \\
Sster6 & Australia & - & 501 & JX489151.1 & Sultana et al. [41] \\
Sster7 & Australia & - & 501 & JX489149.1 & Sultana et al. [41] \\
\hline
\end{tabular}

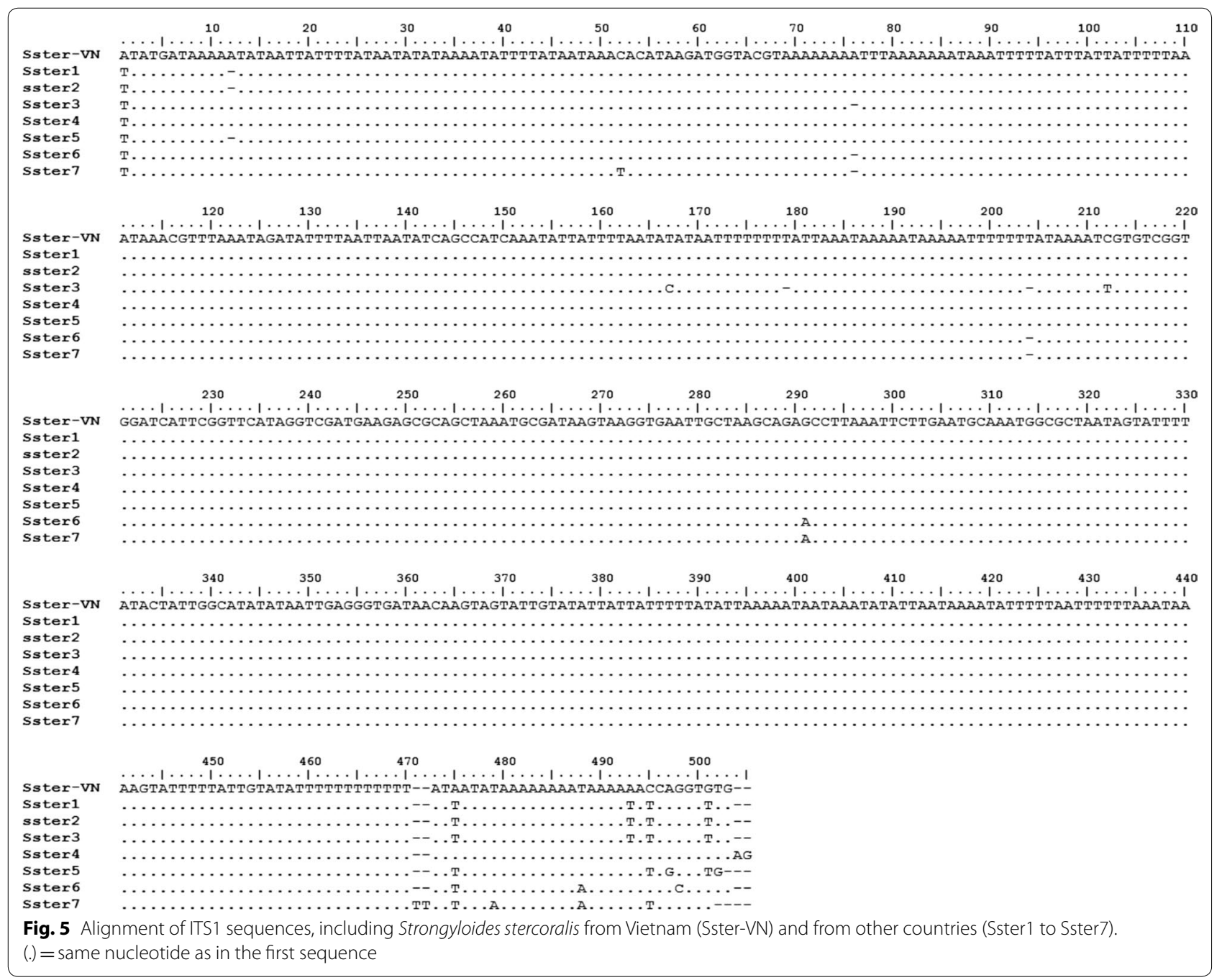

disease. The statistically significant rural/urban relationship of $22.37 \% / 14.59 \%$ found in our patients agrees with the previous analyses [35].

The overall geographical distribution of human strongyloidiasis in Vietnam fits the appropriate climate factor values of maximum temperature, minimum temperature, humidity and rainfall throughout the country (Fig. 7). The aforementioned seroprevalences found by other authors [35] and those found in the present study in northern Vietnam correspond well with the 


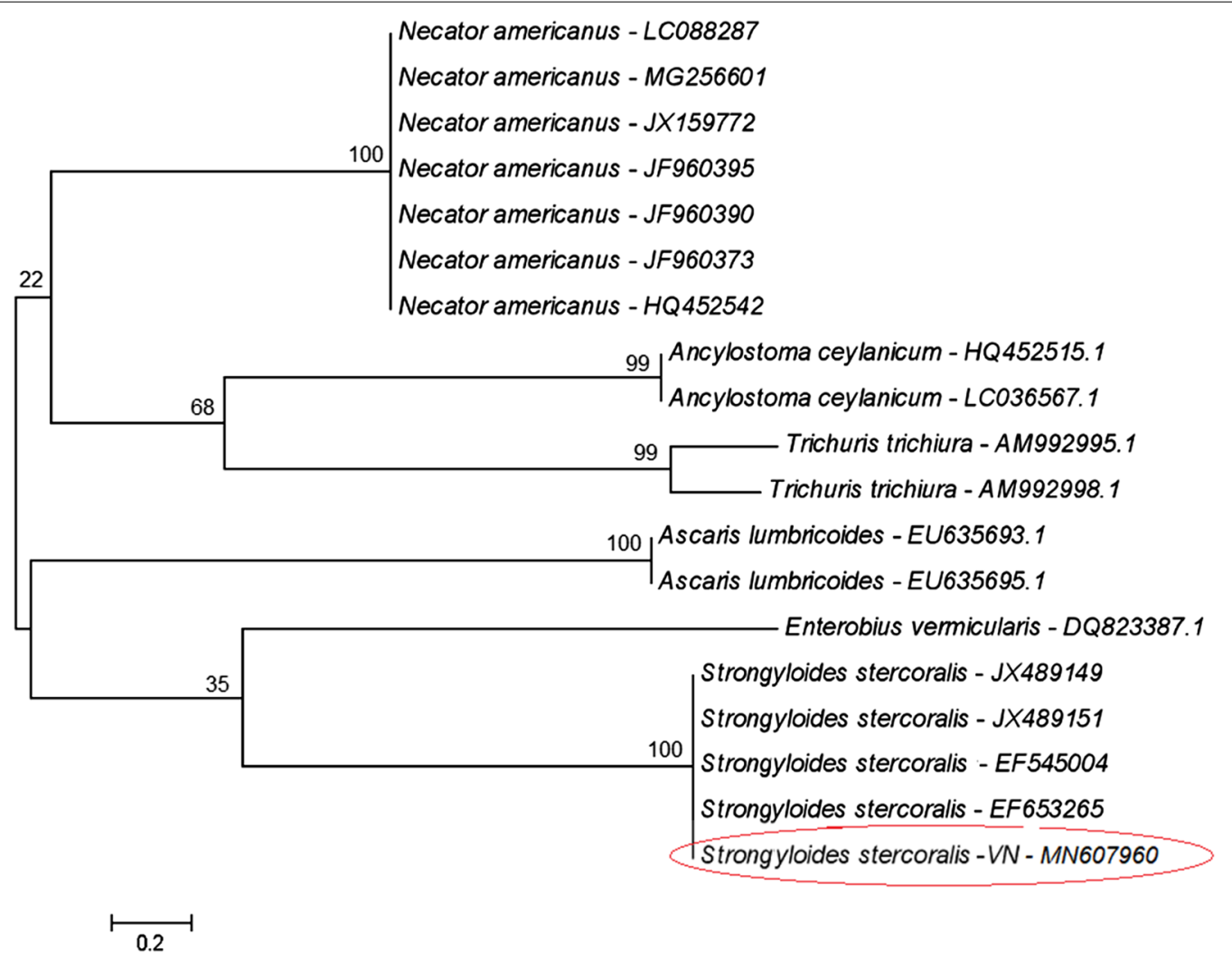

Fig. 6 Phylogenetic tree based on ITS1 sequence data including Strongyloides stercoralis from Vietnam (VN) and from other countries, together with other human-infecting nematode species available on GenBank

warm temperatures and very high humidity, when taking into account geographical characteristics (north or south location, inland highland or coastal lowland) and human settlement types (urban or rural). Regarding the environmental characteristics which may be considered from the point of view of disease transmission, i.e. the free-living stages of S. stercoralis in the soil (adults, larvae), the differences of temperatures throughout the year between the north (represented by Hanoi) and the south (represented by Ho Chi Minh and Dak Lak) concerning seasonality should be highlighted. Thus, whereas in Hanoi temperatures decrease pronouncedly during the winter months (November to February), in Ho Chi Minh and Dak Lak temperatures appear to be stably high the year long (Fig. 7). Given that the duration of time in the environment of the external cycle of $S$. stercoralis is limited to three weeks maximum in an optimum environment, a temperature of $20-28{ }^{\circ} \mathrm{C}$ [5], this indicates that in northern latitudes of Vietnam the external cycle may be highly restricted or stopped during winter, whereas on the contrary it may continuously give rise to subsequent generations in southern latitudes. This may explain the higher prevalences in the south when compared to the north.
The aspect of altitude influence in northern Vietnam also merits a comment. Seroprevalences in mountainous areas showed to be slightly lower than in the lowland plains of the wide valley (Fig. 1c). This may be most probably related to the higher human densities facilitating human infection in the lowlands.

In our results, the prevalence in males was only slightly higher than in females, the difference lacking statistical significance. This result does not agree with previous surveys in this country in which a significantly higher prevalence was found in males [35].

The very low number of patients, in whom Strongyloides larvae were found in stools, highlights the low sensitivity of the coprological diagnosis of this disease by larvae detection, in agreement with previous studies [25-27].

The distribution of prevalences and symptoms according to age allows for interesting conclusions. Seroprevalences, diarrhoea, digestive disorders, stomachache, stomach and duodenal ulcers, itching, fever and bloody stool (Table 1, Fig. 4) showed slowly increasing curves with increasing age groups which suggests: (i) infection may most probably occur during early child period; (ii) accumulative individual infections in people occurs 

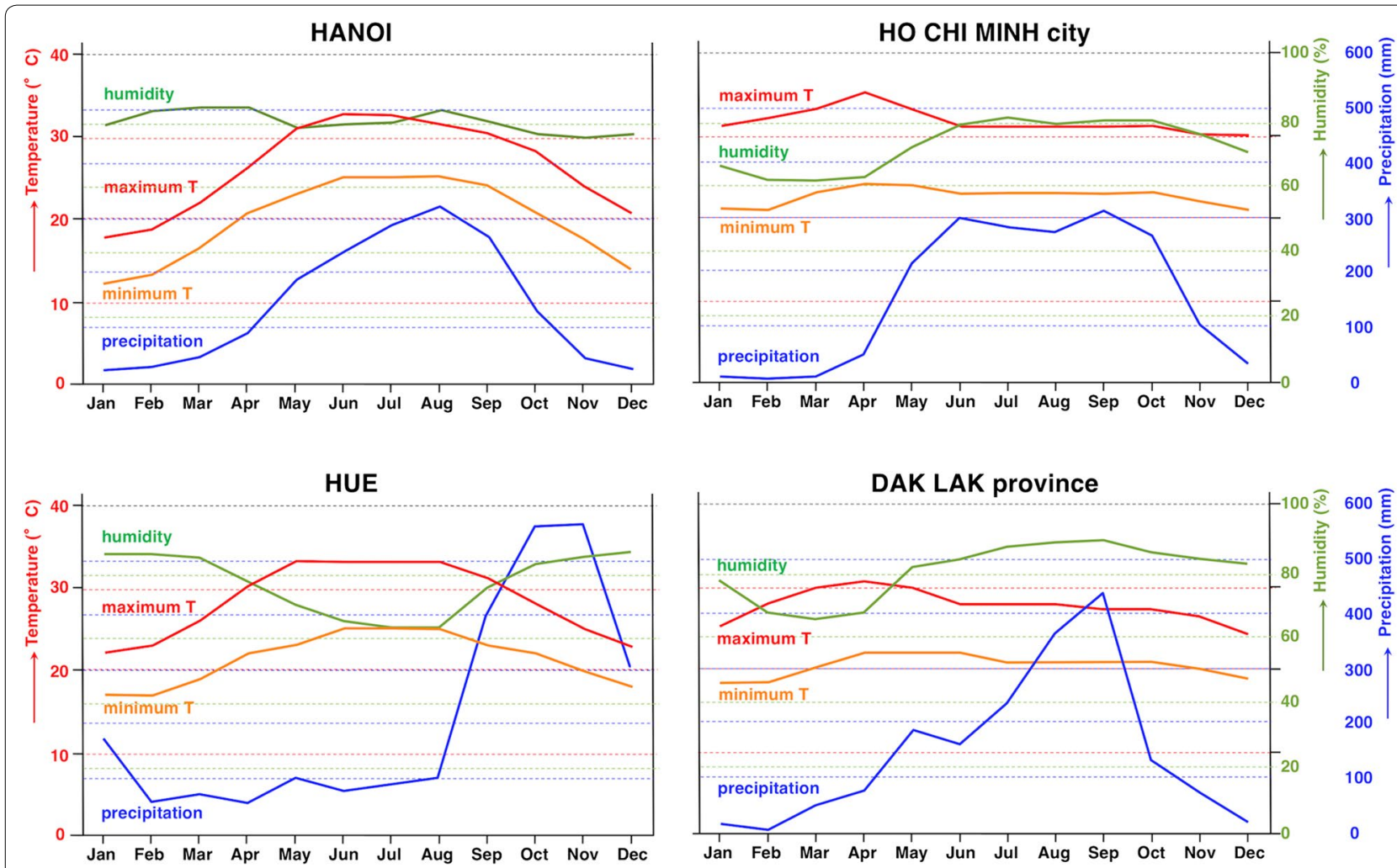

Fig. 7 Mean monthly values of climate factors influencing the external cycle of Strongyloides stercoralis in (i) Hanoi city representing the northern Vietnam area studied and where the Medical University Hospital receiving the patients studied is located; (ii) Ho Chi Minh city in southern Vietnam lowland; (iii) Hue in the central coast area; and (iv) Dak Lak province in rural south-central highlands

during life; and (iii) long-term chronicity may be common in infected subjects, mainly in the older age groups. In its turn, this suggests that subjects infected by Strongyloides may not go to the hospital for diagnosis and treatment for a long time, until the symtomatology becomes sufficiently worrying. These suggestions are supported by the following considerations: (i) it is well known that $S$. stercoralis can lead to a long-lasting infection; (ii) most of the $S$. stercoralis infections are asymptomatic, so symptoms will not be a key factor for asking for treatment, mainly in children; (iii) the patients examined were not following current and previous or past anti-Strongyloides treatments; (iv) there are insufficient conditions of hygiene and sanitation in the rural and also the poor urban areas from where the patients live, and (iv) aged people in those areas mainly depend on agricultural activities in the field.

From the point of view of disease epidemiology, the problem becomes evident if outdoor defecation is practised by these infected subjects, thus assuring the transmission of strongyloidiasis in the area. This will also be the case if the sewage systems cause human stools to be deposited into areas where humans may put bare parts of their skin into direct contact with the contaminated soil, which may take place in Hanoi city surrounding suburbs and rural areas. In that sense, the relatively high proportion of patients $(3.5 \%, 14 / 400)$ showing creeping eruption skin lesions should be highlighted. Indeed, these lesions fit typical cutaneous larva migrans infections by animal hookworms, thus referring to the same soil infection source by direct skin contact. Cutaneous larva migrans syndromes are caused by many different species of hookworms of dogs and cats such as most frequently Ancylostoma brasiliense, but also secondarily A. caninum, A. ceylanicum, and rarely Uncinaria stenocephala. The serpiginous cutaneous lesions found in the patients suggest that $A$. brasiliense or A. ceylanicum were involved, according to the characteristics of the skin lesions which appear to be clearly different from those caused by A. caninum [42]. The causal agent of the creeping eruption lesions in our patients should be ascribed to A. ceylanicum, taking into account the recent molecular re-evaluation of dog ancylostomids in Vietnam which demonstrated that this is the dog hookworm species present in this country instead of the previously recorded $A$. brasiliense [43]. 
Interestingly, cutaneous larva migrans lesions were also found in the posterior limbs in $4 \%$ of 50 strongyloidiasis-seropositive patients in another study of communities in Vietnam [36]. Symptoms related to Strongyloides infection in this study included abdominal pain in $88 \%$ of the patients, irregular and intermittent loose stool in $46 \%$, swelling and urticaria in $74 \%$, headache in $78 \%$ and weight loss in $12 \%$.

The analysis of the 501-bp nucleotide sequence of the ITS1 rDNA by comparison with the same sequence marker of the species $S$. stercoralis from other countries revealed very few nucleotide differences. When considering the value of the ITS1 as a marker of species [38], it may be concluded that the Vietnamese nematode belongs to the species S. stercoralis.

To our knowledge, this is the first molecular identification of S. stercoralis in Vietnam. To date, this marker has been obtained from S. stercoralis only in Australia [41], Iran [44] and Indonesia [45]. Other DNA markers have more frequently been used for the molecular diagnosis of $S$. stercoralis infection, such as the small subunit $18 \mathrm{~S}$ rRNA gene [46-48] and mitochondrial DNA cox1 gene $[48,49]$. The $18 S$ gene is a highly conserved sequence [38] which may be used to differentiate other nematode or helminths infecting humans (as clearly illustrated by our phylogenetic tree in which very low bootstrap values appear in the main nodes; Fig. 6), whereas the cox 1 gene is a more variable marker which may be more useful to analyze intraspecific or inter-population variability [38]. Thus, ITS1 becomes more appropriate for interspecific differentiation, which in the case of Strongyloides spp. infection in humans becomes important due to the existence of another Strongyloides species able to infect humans, S. fuelleborni $[45,47,50]$ or even non-Strongyloides rhabditids which may appear in human stools [51].

\section{Conclusions}

To our knowledge, this study is the largest survey of human strongyloidiasis in Vietnam to date and the first molecular identification of S. stercoralis in the country. Further molecular studies of $S$. stercoralis-infected patients from throughout Vietnam with the same DNA marker are needed to assess the potential intraspecific variability and thus enable conclusions about the zoonotic origin of human infections. This may help in designing appropriate control measures at the level of animal reservoirs and transmission pathways. The higher seroprevalences in rural areas than in urban areas, both in general and individually in all provinces without exception, indicates the convenience to concentrate epidemiological efforts in rural areas not yet surveyed in Vietnam. The higher prevalence of $44.7 \%$ recently found by coprological methods in rural Cambodia [52] suggests that a higher public health problem by $S$. stercoralis may be present in more remote areas. Long-term chronicity may be common in infected subjects, mainly in the older age groups. The stable high temperatures in southern Vietnam and seasonal temperatures including cooler winters in the northern Vietnam may explain the lower prevalences in the north.

\section{Abbreviations \\ ELISA: enzyme-linked immunosorbent assay; ITS1: internal transcribed spacer 1. \\ Acknowledgements \\ All staff of the NAFOSTED project are acknowledged for their contribution to the analysis of the data.}

\section{Author's contributions}

NVD wrote the first draft of the manuscript. PNM analysed the data. LVD carried out the molecular analyses. SM-C corrected the text, contributed to the epidemiological interpretation and wrote the final version of the paper. All authors read and approved the final manuscript.

\section{Funding}

This research was funded by Vietnam National Foundation for Science and Technology Development (NAFOSTED) under Grant No. 108-05-2017.301. Spanish collaboration funded by the project no. RD16/0027/0023, Red de Investigación Cooperativa en Enfermedades Tropicales-RICET, of the National Program I+D+I 2008-2011, ISCIII-Subdirección General de Redes y Centros de Investigación Cooperativa, Ministry of Health and Consumption, Madrid, Spain.

\section{Availability of data and materials}

Data supporting the conclusions of this article are included within the article. The newly generated sequence was submitted to the GenBank database under the accession number MN607960.

\section{Ethics approval and consent to participate}

This study was approved by the Institutional Review Board for Ethics in Biomedical Research, Hanoi Medical University, Ministry of Health. Patients visited the hospital for diagnosis and treatment. Consent was obtained individually from each patient during medical consultation. Patients for this study were collected by physicians in Hanoi Medical Hospital and National Hospital of Tropical Diseases.

\section{Consent for publication}

Not applicable.

\section{Competing interests}

The authors declare that they have no competing interests.

\section{Author details}

${ }^{1}$ Hanoi Medical University, 01 Ton That Tung, Hanoi, Vietnam. ${ }^{2}$ National Hospital of Tropical Diseases 78 Giai Phong, Hanoi, Vietnam. ${ }^{3}$ Departamento de Parasitología, Facultad de Farmacia, Universidad de Valencia, Av. Vicent Andrés Estellés s/n, Burjassot, 46100 Valencia, Spain.

Received: 26 March 2019 Accepted: 29 October 2019

Published online: 04 November 2019

\section{References}

1. WHO. Strongyloidiasis. Geneva: World Health Organization; 2019. http:// www.who.int/intestinal_worms/epidemiology/strongyloidiasis/en/. Accessed 22 Aug 2019.

2. Greaves D, Coggle S, Pollard C, Aliyu SH, Moore EM. Strongyloides stercoralis infection. Br Med J. 2013;347:f4610. 
3. Schär F, Trostdorf U, Giardina F, Khieu V, Muth S, Marti H, et al. Strongyloides stercoralis: global distribution and risk factors. PLoS Negl Trop Dis. 2013;7:e2288

4. Puthiyakunnon S, Boddu S, Li Y, Zhou X, Wang C, Li J, et al. Strongyloidiasis-an insight into its global prevalence and management. PLoS Negl Trop Dis. 2014;8:e3018.

5. Page W, Jenni A, Judd JA, Bradbury RS. The unique life cycle of Strongyloides stercoralis and implications for public health action. Trop Med Infect Dis. 2018:3:53.

6. De NV, Than PV, Lien PTH, Minh PN, Dan HT, Phuong TK, et al. Medical parasites. Education book for medical doctors. Hanoi: Academic Press; 2016. p. 144-85.

7. Miyazaki I. An Illustrated Book of Helminthic zoonoses. International Medical Foundation of Japan, Shukosha Printing. Fukuoka: SEAMIC Publication; 1991. p. 355-62.

8. Nonaka D, Takaki K, Tanaka M, Umeno M, Takeda T, Yoshida M, et al. Paralytic ileus due to strongyloidiasis: case report and review of the literature. Am J Trop Med Hyg. 1998;59:535-8.

9. Nabeya D, Haranaga S, Kinjo T, Parrott G, Uehara A, Nahar S, et al. Pulmonary manifestations in severe strongyloidiasis: review of 17 cases. Eur Respir J. 2015;46:PA757.

10. Makker J, Balar B, MNiazi M, Daniel M. Strongyloidiasis: a case with acute pancreatitis and a literature review. World J Gastroenterol. 2015;21:3367-75.

11. Paltridge M, Traves A. The health effects of strongyloidiasis on pregnant women and children: a systematic literature review. Trop Med Infect Dis. 2018;3:50.

12. Hagelskjær LH. A fatal case of systemic strongyloidiasis and review of the literature. Eur J Clin Microbiol Infect Dis. 1994;13:1069-74.

13. Lim S, Katz K, Krajden S, Fuksa M, Keystone JS, Kain KC. Complicated and fatal Strongyloides infection in Canadians: risk factors, diagnosis and management. J Can Med Ass. 2004;171:479-84.

14. Gorman SR, Craven DE. Strongyloides stercoralis hyperinfection. New Engl J Med. 2008;359:11

15. Tefé-Silva C, Machado ER, Faccioli LH, Ramos SG. Hyperinfection syndrome in strongyloidiasis. Curr Top Trop Med. 2012;22:377-96.

16. Buonfrate D, Requena-Mendez A, Angheben A, Muñoz J, Gobbi F, van den Ende J, et al. Severe strongyloidiasis: a systematic review of case reports. BMC Infect Dis. 2013;13:78.

17. Hassan IFK, de Farias B, Jannke HA, Kopereck VV, da Silva JF, Gonzales RG. Duodenal strongyloidiasis and hyperinfection syndrome: case report and literature review. Clin Biomed Res. 2016:36:50-3.

18. Albonico M, Becker SL, Odermatt P, Angheben A, Anselmi M, Amor A, et al. StrongNet: an international network to improve diagnostics and access to treatment for strongyloidiasis control. PLoS Negl Trop Dis. 2016;10:e0004898.

19. Corti M. Strongyloides stercoralis in immunosuppressed patients. Arch Clin Infect Dis. 2016;11:e27510

20. Bar-Yoseph H, Zohar Y, Lorber M. Strongyloidiasis-related IRIS: a case report and literature review. J Int Ass Prov AIDS Care. 2017;16:8-10.

21. Schaeffer MW, Buell JF, Gupta M, Conway GD, Akhter SA, Wagoner LE. Strongyloides hyperinfection syndrome after heart transplantation: case report and review of the literature. J Heart Lung Transplant. 2004;23:905-9.

22. Keiser PB, Nutman TB. Strongyloides stercoralis in the immunocompromised population. Clin Microbiol Rev. 2004;17:208-17.

23. Fardet L, Généreau T, Poirot JL, Guidet B, Kettaneh A, Cabane J. Severe strongyloidiasis in corticosteroid-treated patients: case series and literature review. J Infect. 2007;54:18-27.

24. Brumpt LC, Sang HT. Larva currens seul signe pathognomonique de la strongyloïdose. Ann Parasitol Hum Comp. 1973;48:319-28.

25. Buonfrate D, Formenti F, Perandin F, Bisoffi Z. Novel approaches to the diagnosis of Strongyloides stercoralis infection. Clin Microbiol Infect. 2015;21:543-52.

26. Buonfrate D, Gobbi F, Angheben A, Bisoffi Z. Strongyloides stercoralis: the need for accurate information. Lancet. 2018:391:2322-3.

27. Mendes T, Minori K, Ueta M, Miguel DC, Allegretti SM. Strongyloidiasis current status with emphasis in diagnosis and drug research. J Parasitol Res. 2017;2017:5056314.

28. Tuyizere A, Ndayambaje A, Walker TD, Bayingana C, Ntirenganya C, Dusabejambo V, et al. Prevalence of Strongyloides stercoralis infection and other soil-transmitted helminths by cross-sectional survey in a rural community in Gisagara District, Southern Province, Rwanda. Trans Roy Soc Trop Med Hyg. 2018;112:97-102.

29. Conlan JV, Khamlome B, Vongxay K, Elliot A, Pallant L, Sripa B, et al. Soiltransmitted helminthiasis in Laos: a community-wide cross-sectional study of humans and dogs in a mass drug administration environment. Am J Trop Med Hyg. 2012;86:624-34.

30. Azira NMS, Abdel Rahman MZ, Zeehaida M. Review of patients with Strongyloides stercoralis infestation in a tertiary teaching hospital, Kelantan. Malaysian J Pathol. 2013;35:71-6.

31. Jongwutiwes $U$, Waywa D, Silpasakorn S, Wanachiwanawin D, Suputtamongkol Y. Prevalence and risk factors of acquiring Strongyloides stercoralis infection among patients attending a tertiary hospital in Thailand. Path Global Health. 2014;108:137-40.

32. Pelletier LL Jr, Gabre-Kidan T. Chronic strongyloidiasis in Vietnam veterans Am J Med. 1985;78:139-40.

33. Lam BV, Trung DD, Thanh DT. Situation of Strongyloides stercoralis infection in Phu Binh district, Thai Nguyen province and Ha Hoa district, Phu Tho province. J Malaria Parasit Contr. 2014;3:10-4.

34. Nguyen T, Cheong FW, Liew JWK, Lau LL. Seroprevalence of fascioliasis, toxocariasis, strongyloidiasis and cysticercosis in blood samples diagnosed in Medic Medical Center Laboratory, Ho Chi Minh City, Vietnam in 2012. Parasit Vectors. 2016;9:486.

35. Diep NTN, Thai PQ, Trang NNM, Jägers J, Fox A, Horby P, et al. Strongyloides stercoralis seroprevalence in Vietnam. Epidemiol Infect. 2017;145:3214-8.

36. Duc VL, Hong TT, Du W. Clinical manifestations and ivermectin effectiveness on human Strongyloides stercoralis infection in Duc Hoa district, Long An province. J Malaria Parasit Contr. 2017;5:24-9.

37. De NV, Van KP. Parasitic zoonoses. Hanoi: Education Publishing House; 2009. p. 260.

38. Mas-Coma S, Bargues MD. Populations, hybrids and the systematic concepts of species and subspecies in Chagas disease triatomine vectors inferred from nuclear ribosomal and mitochondrial DNA. Acta Trop. 2009:110:112-36.

39. Romstad A, Gasser RB, Monti JR, Polderman AM, Nansen P, Pit DS, Chilton NB. Differentiation of Oesophagostomum bifurcum from Nectator americanus by PCR using genetic markers in spacer ribosomal DNA. Mol Cell Prob. 1997:11:169-76.

40. Moghaddassani H, Mirhendi H, Hosseini M, Rokni MB, Mowlavi GH, Kia EB. Molecular Diagnosis of Strongyloides stercoralis Infection by PCR Detection of Specific DNA in Human Stool Samples. Iran J Parasitol. 2011;6(2):23-30.

41. Sultana Y, Fanrong KK, Rady Gilbert GL, Lee R. Internal transcribed spacer region 1 (ITS1) as promising target for detection of intra-specific polymorphisms for Strongyloides stercoralis. 8th National Workshop on Strongyloidiasis, March 23-24, 2013, Canberra, Australia.

42. Euzeby J. Les zoonoses helminthiques. Paris: Vigot Frères Editeurs; 1964. p 389.

43. Ng-Nguyen D, Hii SF, Nguyen VAT, Nguyen TV, Nguyen DV, Traub RJ. Re-evaluation of the species of hookworms infecting dogs in Central Vietnam. Parasit Vectors. 2015:8:401.

44. Kia EB, Rahimi HR, Mirhendi H, Nilforoushan MR, Talebi A, Zahabiun F, et al. A case of fatal strongyloidiasis in a patient with chronic lymphocytic leukemia and molecular characterization of the isolate. Kor J Parasitol. 2008:46:261-3.

45. Labes EM, Wijayanti N, Deplazes P, Mathis A. Genetic characterization of Strongyloides spp. from captive, semi-captive and wild Bornean orangutans (Pongo pygmaeus) in Central and East Kalimantan, Borneo, Indonesia. Parasitology. 2011;138:1417-22.

46. Dorris M, Mark E, Viney ME, Blaxter ML. Molecular phylogenetic analysis of the genus Strongyloides and related nematodes. Int J Parasitol. 2002:32:1507-17.

47. Schär F, Guo L, Steit A, Khieu V, Muth S, Marti H, et al. Strongyloides stercoralis genotypes in humans in Cambodia. Parasitol Int. 2014;63:533-6.

48. Laymanivong S, Hangvanthong B, Insisiengmay B, Vanisaveth $V$, Laxachack $P$, Jongthawin J, et al. First molecular identification and report of genetic diversity of Strongyloides stercoralis, a current major soil-transmitted helminth in humans from Lao People's Democratic Republic. Parasitol Res. 2016;115:2973-80

49. Thanchomnang T, Intapan PM, Sanpool O, Rodpai R, Tourtip S, Yahom S, et al. First molecular identification and genetic diversity of Strongyloides 
stercoralis and Strongyloides fuelleborni in human communities having contact with long-tailed macaques in Thailand. Parasitol Res. 2017;116:1917-23.

50. Terashima A, Canales M, Tello R, Mas-Coma S, Esteban JG, Bargues MD, et al. Strongyloides fuelleborni: reporte del primer caso clínico en el Perú. Diagnóstico, Lima. 2000;39:199-203.

51. Stachurska-Hagen T, Johnsen OH, Robertson LJ. Non-Strongyloides rhabditida identified in fecal samples - two case reports: lessons learned from morphological and molecular diagnostic approaches. Parasitol Open. 2016;2:e14.
52. Khieu V, Schär F, Forrer A, Hattendorf J, Marti H, Duong S, et al. High prevalence and spatial distribution of Strongyloides stercoralis in rural Cambodia. PLoS Negl Trop Dis. 2014;8:e2854.

\section{Publisher's Note}

Springer Nature remains neutral with regard to jurisdictional claims in published maps and institutional affiliations.
Ready to submit your research? Choose BMC and benefit from:

- fast, convenient online submission

- thorough peer review by experienced researchers in your field

- rapid publication on acceptance

- support for research data, including large and complex data types

- gold Open Access which fosters wider collaboration and increased citations

- maximum visibility for your research: over $100 \mathrm{M}$ website views per year

At BMC, research is always in progress.

Learn more biomedcentral.com/submissions 